\title{
PRÁTICAS DE LETRAMENTOS VERNACULARES EM LÍNGUA INGLESA: A PRÁXIS NA APRENDIZAGEM ALÉM DO CURRÍCULO FORMAL DA UNIVERSIDADE
}

\author{
PRÁCTICAS VERNACULARES DE LITERACIDAD EN LENGUA INGLESA: LA \\ PRÁXIS EN EL APRENDIZAJE MÁS DEL CURRÍCULO FORMAL DE LA \\ UNIVERSIDAD
}

VERNACULAR LITERACY PRACTICES IN THE ENGLISH LANGUAGE: PRAXIS IN LEARNING BEYOND THE UNIVERSITY FORMAL CURRICULUM

\author{
Caique Fernando FISTAROL ${ }^{1}$ \\ Adriana FISCHER ${ }^{2}$ \\ Cyntia BAILER ${ }^{3}$
}

Caique Fernando da Silva Fistarol

Currículo lattes: http://lattes.cnpq.br/7333197195049793

Adriana Fischer

Currículo lattes: http://lattes.cnpq.br/3344987638930485

Cyntia Bailer

Currículo lattes: http://lattes.cnpq.br/3682466148530707

RESUMO: As práticas de letramentos vernaculares em língua inglesa têm se tornado temática de pesquisa a partir do crescente uso de tecnologias digitais (TD) nos contextos formais e informais de aprendizagem. Este artigo objetiva analisar práticas de letramentos vernaculares adotadas por licenciandas de um curso de Letras, no que se refere aos

${ }^{1}$ Universidade Regional de Blumenau (FURB), Blumenau - SC - Brasil. Secretaria Municipal de Educação de Blumenau (SEMED), Blumenau, SC - Brasil. Coordenador Curricular de Línguas Estrangeiras do Ensino Fundamental. ORCID: https://orcid.org/0000-0001-7650-7324. E-mail: caiquefistarol@blumenau.sc.gov.br; cfersf@gmail.com

${ }^{2}$ Universidade Regional de Blumenau (FURB), Blumenau - SC - Brasil. Fundação Universidade Regional de Blumenau (FURB), Blumenau - Santa Catarina - Brasil. Vice coordenadora e Professora do Programa de PósGraduação em Educação (Mestrado e Doutorado). ORCID: https://orcid.org/0000-0001-9787-2814. E-mail: adrfischer@furb.br

${ }^{3}$ Universidade Regional de Blumenau (FURB), Blumenau - SC - Brasil. Professora no Programa de PósGraduação, Mestrado em Educação da FURB. Doutora em Linguística, pela Universidade Federal de Santa Catarina, Brasil. ORCID: https://orcid.org/0000-0002-9049-8003. E-mail: cbailer@ furb.br 
letramentos em língua inglesa. Para tanto, adota-se a perspectiva etnográfica, com abordagem qualitativa e a amostra constitui-se por três licenciandas de uma universidade do estado de Santa Catarina, Brasil, as quais participaram de uma entrevista semiestruturada acerca do tema. A partir de técnicas de análise de conteúdo foram criadas oito categorias de análise que permitiram constatar, a partir dos depoimentos das entrevistadas, que o uso das TD é importante para a aprendizagem da língua inglesa, tanto no que se refere ao seu uso cotidiano quanto em suas práticas pedagógicas. Por fim, os dados indicam que práticas de letramentos vernaculares ressignificam a elaboração de planejamento pedagógico, a ação docente e, consequentemente a práxis na aprendizagem da língua inglesa para além do currículo formal da universidade.

PALAVRAS-CHAVE: Práticas de letramentos vernaculares. Letramentos acadêmicos. Língua inglesa. Tecnologias digitais.

RESUMEN: Las prácticas vernaculares de literacidad en lengua inglesa se han vuelto temáticas de investigación a partir del creciente uso de tecnologías digitales (TD) en los contextos formales e informales de aprendizaje. Este artículo objetiva analizar prácticas vernaculares adoptadas por licenciandas del curso de Letras, en lo que se refiere a las prácticas de literacidad en inglés. Para tanto, se adopta la perspectiva etnográfica, con abordaje cualitativo y la muestra se constituye por tres licenciandas de una universidad del estado de Santa Catarina, Brasil, las cuales fueron sometidas a una entrevista semiestructurada acerca del tema. A partir de técnicas de análisis de contenido se crearon ocho categorías de análisis que nos permitieron constatar, a partir de los testimonios de las entrevistadas, que el uso de las TD es importante para el aprendizaje de la lengua inglesa, tanto en lo que se refiere a su uso cotidiano como en sus prácticas pedagógicas. Por último, los datos indican que las prácticas vernaculares resignifican la elaboración de planificación, la acción docente y, consecuentemente, la praxis en el aprendizaje de la lengua inglesa más allá del currículo formal de la universidad.

PALABRAS-CLAVE: Prácticas vernaculares de literacidad. Literacidades académicas. Inglés. Tecnologías Digitales.

ABSTRACT: Vernacular literacy practices in English have become a research topic based on the increasing use of digital technologies (DT) in formal and informal contexts of learning. Therefore, this article aims to analyze the vernacular practices adopted by Letras undergraduate students, as regards their English language literacy practices. To do so, the ethnographic perspective was adopted, with a qualitative approach, and the sample consisted of semi-structure interviews with three undergraduates from a university in the state of Santa Catarina, Brazil. The collected material was explored through content analysis techniques to create categories of analysis about the interviewees' discourses. Eight categories of analysis were created to allow us to verify, from the interviewees' statements, that the use of DT is important for learning English, both in terms of daily use and pedagogical practices. Finally, the data revealed that vernacular practices re-signify the elaboration of planning, teaching action and, consequently, the praxis in learning English beyond the university formal curriculum.

KEYWORDS: Vernacular literacy practices. Academic literacies. English language. Digital technologies. 


\section{Introdução}

Os letramentos acadêmicos com o uso das tecnologias digitais (TD) têm se tornado temática de pesquisa, na medida em que as TD são utilizadas pelos indivíduos nos diferentes espaços e tempos. O uso das TD possibilita a aquisição de novos conhecimentos em ambientes formais - instituições de ensino, locais de trabalho, cursos de formação continuada - e informais - locais de aprendizagem onde não há um currículo definido ou um planejamento pré-determinado.

Parte-se do pressuposto de que os letramentos acadêmicos estão relacionados ao domínio não apenas dos códigos da leitura e escrita, mas aos seus usos sociais em contextos considerados escolares/acadêmicos. E esses usos sociais preveem leitura crítica e contextualizada dos textos, considerando seus diferentes elementos: identidade, tempo e espaço da sua produção, relações de poder envolvidas, produção de sentidos, entre outros.

A partir da introdução das TD nos processos de aprendizagem, bem como na vida das pessoas em geral, observa-se que há uma ampliação no leque de possibilidades de acesso à informação e ao conhecimento, o que, em perspectiva, auxilia o processo de letramentos acadêmicos dos que têm acesso e compreendem os códigos dos recursos tecnológicos.

A temática sobre os letramentos acadêmicos (LEA; STREET, 2006) com o uso de TD e, especificamente, as práticas vernaculares (CASSANY; HERNÁNDEZ, 2012) em língua inglesa, se justifica visto que no curso de licenciatura em Letras pesquisado não há, no currículo acadêmico, disciplinas específicas para desenvolver habilidades de compreensão e de escrita do inglês com o uso das TD, todavia há uma exigência de leitura de materiais produzidos na língua inglesa por meio do uso de tecnologias.

Com isso, tem-se como objetivo analisar práticas vernaculares adotadas por licenciandas de Letras, no que se refere aos letramentos em língua inglesa e examinar se as participantes fizeram uso de algum recurso tecnológico para aprendizagem. Considera-se indispensável que se parta do conhecimento voltado às relações sociais para que o educador e os estudantes construam uma práxis, isto é, articulem reflexões entre o educativo, o político e a vida prática, promovendo a conscientização e, em perspectiva, a transformação social.

As práticas vernaculares constituem-se como parte dos letramentos em uma língua, e nesta pesquisa, especificamente, a análise recai sobre práticas vernaculares em língua inglesa. De maneira geral, essas práticas podem ser realizadas de maneira individual ou na relação entre pares: docentes, amigos, parentes, colegas de trabalho, conhecidos. Além disso, cada pessoa desenvolve processos particulares a partir de sua necessidade, seja ela imediata ou a 
longo prazo, portanto, práticas vernaculares podem ser desenvolvidas a partir do conhecimento de outras estratégias de aprendizagem como, por exemplo, a partir do uso das TD.

Para alcançar os objetivos desta pesquisa, adotou-se como método uma abordagem etnográfica interpretativista (FRITZEN, 2012), qualitativa (VÓVIO; SOUZA, 2005), em que os objetivos são exploratórios e a amostra é constituída por três licenciandas ${ }^{4}$.

A coleta de dados iniciou no final do ano de 2016, com um questionário respondido por uma turma de estudantes do oitavo semestre do curso de Letras em questão. Com o questionário, o objetivo foi mapear a construção histórica-social dos sujeitos, desde o período inicial da formação docente das licenciandas até sua atuação como docentes. A partir da realização do questionário, foram selecionadas três estudantes para a participação de uma entrevista semiestruturada que ocorreu no primeiro semestre de 2017. As participantes foram selecionadas a partir de aspectos singulares de suas trajetórias e experiências com a língua inglesa.

A escolha pelas entrevistas semiestruturadas se justifica à medida que estas oferecem ao entrevistador uma maior possibilidade de manter-se focado nos seus objetivos e também permite que o entrevistado/a tenha mais liberdade para expor as suas ideias. Nesse sentido, Bauer e Gaskell (2002, p. 73) esclarecem que "as perguntas são quase que um convite ao entrevistado para falar longamente, com suas próprias palavras e com tempo para refletir". Portanto, com a entrevista semiestruturada, conforme Triviños (1987), o entrevistador tem um roteiro a seguir, criado a partir dos objetivos do estudo e da literatura da área, porém com maior flexibilidade para questionar sobre detalhes que vão surgindo conforme o participante vai respondendo e refletindo, detalhes que podem auxiliar na posterior análise dos dados.

Para a exploração do material coletado, optou-se pela análise de conteúdo (BARDIN, 1977), pois permite a construção de categorias de interpretação emergentes sobre as manifestações das entrevistadas. Ao falar em análise de conteúdo, faz-se referência a "um conjunto de técnicas de análise das comunicações, visando a obter, [...] indicadores quantitativos ou não, que permitam a inferência de conhecimentos relativos às condições de produção/recepção (variáveis inferidas) das mensagens” (BARDIN, 1977, p. 34).

Com essa breve contextualização da pesquisa, dividiu-se este artigo nas seguintes seções: os letramentos acadêmicos e a aprendizagem da língua inglesa; práticas de letramentos vernaculares como possibilidades de aprendizagem; o uso das TD para

\footnotetext{
${ }^{4}$ Para preservar o anonimato das entrevistadas, utilizam-se pseudônimos escolhidos por elas: Frida, Capitu e Catarina.
} 
aprendizagem colaborativa; práticas de letramentos vernaculares e aprendizagem da língua inglesa a partir dos depoimentos das entrevistadas; e as considerações finais.

\section{Os letramentos acadêmicos e a aprendizagem da língua inglesa}

Os enfoques conceituais em torno dos letramentos acadêmicos e das práticas de letramentos vernaculares, com particularidades referentes à aprendizagem da língua inglesa, são decisivos neste artigo, pois auxiliam na compreensão dos dados que ora se abordam na pesquisa encaminhada com estudantes de Letras. Nessa direção, o fenômeno dos letramentos é, inicialmente, aqui compreendido, de acordo Dionísio (2007, p. 210), como

um conjunto de práticas sociais, que envolvem o texto escrito, não do ponto restrito da linguagem, mas de qualquer texto. Portanto, aí vamos enveredar por um letramento que é plural, envolve, integra outras linguagens que não é apenas a linguagem verbal através dos textos. Então, o sentido plural localiza essas práticas na vida das pessoas, práticas que são realizadas com finalidades para atingir os seus fins específicos de vida, e não um conjunto de competências que estão armazenadas na cabeça das pessoas.

Nesse sentido, também em conformidade com a proposta de Street (2009), o letramento não é mera reprodução neutra de códigos escritos, mas um processo social contextualizado capaz de promover o empoderamento de sujeitos. Diante disso, o conceito de letramento está associado a práticas sociais mais amplas. Ampliando a compreensão sobre o conceito de letramentos (literacidad, em espanhol), em seus diferentes contextos, Cassany e Castella (2010, p. 354, tradução nossa) analisam que

A orientação sociocultural de leitura e escritura (o letramento, conforme o título) sugere que ler e escrever não só são processos pessoais cognitivos ou atos de (des)codificação, mas também tarefas sociais, práticas culturais enraizadas historicamente em uma comunidade de falantes. Além de usar signos e de colocar em jogo processos cognitivos, ao ler fazemos coisas em sociedade, interagimos com nossa família, colegas e concidadãos, exercemos nossos direitos democráticos, nossas obrigações laborais, nossa atividade diária em um entorno letrado.

Com base em teorias que consideram os letramentos sob a perspectiva sociocultural, estudiosos (BARTON, 1994; GEE, 1996; STREET, 1984) dos New Literacy Studies (Novos Estudos de Letramento) se propuseram a explicar, no plano epistemológico, a escrita em contextos acadêmicos. Nessa perspectiva, Lea \& Street (2006) indicam que abordagens para compreensão dos letramentos dos estudantes, inseridos em contextos acadêmicos, podem ser 
concebidas por meio de três modelos: 1) modelo de habilidades de estudo, 2) modelo de socialização acadêmica e 3) modelo de letramentos acadêmicos.

Sinteticamente, segundo Lea e Street (2006) o "modelo de habilidades de estudo" concentra-se nos elementos da superfície da forma da língua e considera que os estudantes podem transferir seu conhecimento de escrita e letramento de um contexto para outro. $\mathrm{O}$ segundo, "modelo de socialização acadêmica", supõe que os discursos disciplinares e os gêneros são relativamente estáveis, portanto, os estudantes adquirem maneiras de falar, escrever, pensar e interagir em práticas de letramento que caracterizam membros de uma comunidade disciplinar ou temática. E o terceiro, "modelo de letramentos acadêmicos", tem relação com a produção de sentido, de identidade, de poder e de autoridade.

Os três modelos coexistem no ambiente acadêmico e auxiliam a compreender como os letramentos acadêmicos e, especificamente neste estudo, como práticas de letramentos vernaculares em língua inglesa integram as trajetórias das licenciandas entrevistadas e de que maneira as pesquisas da área podem contribuir para a análise desses letramentos.

No plano didático, Bailly, Assis e Deneire (2016, p. 7, tradução nossa) colocam a seguinte questão quando pesquisam sobre escrever e aprender a escrever nas universidades do Brasil, da França e do Canadá: “Como ajudar os estudantes a escrever melhor sua língua ou uma outra língua?". A aprendizagem de língua materna ou de outra língua requer, além do ensino dos códigos de leitura e de escrita de determinada língua, sua articulação com as práticas sociais mais amplas e, de maneira mais específica, as dos sujeitos, envolvidos para que o conhecimento seja significativo para os estudantes.

Parte-se, assim, do pressuposto de que as práticas de letramentos são historicamente construídas, por isso, precisam ser compreendidas a partir dos diferentes momentos e contextos históricos. Nesse sentido, Barton e Hamilton (2000, p. 13, tradução nossa) esclarecem que

As práticas de letramento são construídas culturalmente e, como todos os fenômenos culturais, têm suas raízes no passado. Para entender o letramento contemporâneo, é necessário documentar as formas em que o letramento é historicamente situado: as práticas de letramento são tão fluidas, dinâmicas e em mudança quanto as vidas e sociedades das quais fazem parte. Precisamos de uma abordagem histórica para a compreensão da ideologia, da cultura e das tradições em que se baseiam as práticas atuais.

Com apoio nessa citação de Barton e Hamilton (2000), que remete a uma contextualização da aprendizagem das línguas em geral, considera-se necessário, a partir do contexto em que se dá a pesquisa apresentada neste artigo, que o educador construa uma 
articulação entre o educativo, o político e a vida prática. Essa articulação, compreendida por Freire (1996) como práxis, pode promover reflexão e ação nos indivíduos, gerando conscientização e transformação social. Em acréscimo, defende-se que, com o advento das TD e de sua utilização nos diferentes contextos da vida das pessoas, as práticas de letramentos vernaculares se multiplicam e são ressignificadas pelos usuários.

A aprendizagem da língua inglesa, foco de análise neste trabalho, também tem sido ressignificada pelos usuários, pois vem ocorrendo por meio de diferentes contextos, incluindo os formais e os informais, o âmbito institucional e o não institucional, as trocas dentro do ambiente acadêmico e a socialização em outros ambientes, de maneira individual ou coletiva, com ou sem uso das TD.

No contexto de educação formal, particularmente na universidade, e no contexto de formação de professores, os estudantes precisam construir uma postura crítica e a valorização da autonomia é muito importante para que a aprendizagem da língua inglesa permeie o cotidiano dos estudantes. O educador pode auxiliar nesse processo ao possibilitar aos estudantes o desenvolvimento da criticidade. Com relação à escrita universitária, Escorcia e Fenouillet (2011, p. 69, tradução nossa) afirmam que “à universidade, parece necessário levar os alunos a se tornarem conscientes de seus conhecimentos e de suas estratégias mais eficazes, informações que seriam indispensáveis para a autonomia de suas produções escritas".

Com o uso das TD, novas formas de interação são possíveis e o contato com as informações - escritas de maneira coloquial ou vernácula - são ampliadas de tal maneira que há a necessidade de compreendermos os letramentos acadêmicos em língua inglesa com o uso das TD e, especificamente, quais são as práticas vernaculares utilizadas pelos sujeitos desta pesquisa. Na próxima seção, propõe-se um diálogo com alguns teóricos que pesquisam práticas vernaculares, com ênfase às voltadas à interação com as TD, para compreender a que se referem bem como as potencialidades dessas práticas.

\section{Práticas de letramentos vernaculares como possibilidades de aprendizagem}

As práticas de letramentos vernaculares podem ser compreendidas como práticas privadas e informais que podem resultar em aprendizagens relevantes para as pessoas que as utilizam. Essas práticas são flexíveis, livres, desprestigiadas e, por vezes, criticadas diferentemente das práticas acadêmicas que se organizam por meio de um currículo institucional rígido e formal. Por meio de práticas de letramentos vernaculares, as pessoas 
podem desenvolver autonomia para acessar e ressignificar a aprendizagem de uma língua, sem estar no contexto formal, com a possibilidade de acessar assuntos que sejam de interesse pessoal (BAILLY, 2010).

Com relação às alterações nas maneiras de ler e escrever, considerando cada contexto e as estratégias desenvolvidas pelos sujeitos, compreende-se, conforme Cassany (2014a, p. 33, tradução nossa), que

Cada comunidade (língua, país, disciplina, instituição, grupo) cria seus próprios dispositivos (papiros, mesas, livros, blogs, fóruns) para atender as práticas de letramento (cópia, sinal, preencher formulários, compor poemas, ter testes) que eles são obrigados a viver no dia. Além disso, esses artefatos e práticas evoluem ao longo do tempo e do espaço pelo impacto de vários fatores (econômicos, culturais, tecnológicos). Portanto, as formas de ler e escrever variam ao longo do tempo e do espaço para além das diferenças estruturais das línguas.

No que se refere aos usos vernaculares e acadêmicos dos letramentos, Cassany (2014a) enfatiza que há, no mundo letrado, uma lacuna de pesquisas entre o vernáculo e o acadêmico. Dito de outra maneira, as pessoas, sejam adultos ou crianças, aprendem a utilizar a escrita no ambiente acadêmico para construir práticas diferenciadas nos contextos ditos não formais de educação, o que é ainda pouco reconhecido. Dentro dessa compreensão, o uso da internet

[...] conserva, multiplica e redefine as práticas vernaculares. A rede transforma um diário pessoal em um blog ou fotoblog; cria novas formas de interação escrita como o chat ou os fóruns; salva conversas de chat, perfis do Facebook, que até agora eram invisíveis, e torna disponível a todos os utilizadores da Internet. Nunca antes havíamos estado em contato com uma quantidade tão grande de escrita coloquial simplificada, vernácula, por isso é compreensível que cada vez tenha um papel mais relevante para os jovens de hoje (CASSANY; HERNÁNDEZ, 2012, p. 138-139, tradução nossa).

Em consequência a essas relações entre letramentos acadêmicos e vernaculares, há um conjunto diverso de práticas de letramentos e múltiplas formas de linguagem que circulam tanto no contexto acadêmico como fora dele. Essas práticas podem ou não ser valorizadas por determinadas comunidades, e processadas em diferentes domínios sociais, como públicos ou privados.

As práticas vernaculares, como mencionado anteriormente, são livres e autorreguladas, desenvolvidas no contexto da comunidade e diferentes daquelas atividades experienciadas pelos estudantes e reguladas pelos contextos educacionais institucionalizados. Assim, as práticas de letramentos prestigiadas pela escola, pela universidade são pautadas por uma 
concepção dominante de letramento e ainda estão presentes de maneira hegemônica em contextos educacionais e acadêmicos.

$\mathrm{Na}$ próxima seção, procura-se situar o uso das TD nesse processo, visto que as licenciandas entrevistadas as utilizam como ferramenta para a aprendizagem da língua inglesa.

\section{O uso das tecnologias digitais para a aprendizagem colaborativa}

Há algumas décadas vem-se experienciando contextos marcados por espaços e tempos redimensionados, com possibilidades de flexibilidade e ampliação do acesso às TD e, em consequência, à informação. No século XXI, em uma sociedade na qual as TD cada vez mais permeiam o cotidiano das pessoas, faz-se necessário refletir e analisar as suas potencialidades e limites.

Nesse sentido e em referência ao contexto educacional, conforme Zuin (2010, p. 975),

torna-se imperativo refletir sobre o modo pelo qual a educação incorpora as tecnologias, especialmente no que diz respeito à formação de professores e à introdução das tecnologias midiáticas na escola. A transposição das TIC para as práticas educacionais deve ser feita por meio de uma análise minuciosa das suas vantagens e limites, permitindo assim a crítica de uma possível incorporação instrumental e reificada dessas tecnologias.

O uso das TD influencia a vida dos indivíduos em seus diferentes contextos. Com o advento das mídias eletrônicas, uma comunicação mais participativa e envolvente atrai usuários em função das possibilidades que o acesso e uso das TD representam.

A expressão “os meios como extensões do homem”, cunhada por McLuhan (1995), instiga refletir sobre a configuração dessa sociedade, quando os dispositivos passam a ser cada vez mais integrados às pessoas, além de evidenciar a intensidade da relação entre indivíduos e artefatos tecnológicos (TURNES, 2014).

Portanto, percebe-se que as tecnologias estão presentes no cotidiano dos indivíduos, por vezes, do momento em que despertam até o momento de descansar. Não obstante, as pessoas tornam-se residentes digitais (CASSANY, 2014b) à medida que utilizam os ambientes virtuais para auxiliar os processos de aprendizagem.

Cabe ressaltar que as tecnologias como criações humanas deveriam ser incorporadas a práticas de letramentos no sentido de potencializar capacidades humanas, portanto, com um uso de maneira consciente nos diferentes contextos da vida cotidiana. Assim, com a 
incorporação das tecnologias nos diferentes contextos, sobretudo, os educacionais, há a necessidade de se analisar as especificidades da sua utilização, visto que

$\mathrm{O}$ encontro entre a Internet e a pedagogia da autonomia evidencia a necessidade de novos tipos de professores e novos empregos na formação em aprendizagem de línguas, que exigem múltiplas experiências, incluindo habilidades e conhecimentos específicos sobre línguas e culturas, aprendizagem de línguas e ferramentas digitais e comunicação (BAYLLY, 2010, p. 95, tradução nossa).

Quando as pessoas escolhem uma tecnologia para a aprendizagem, pesquisam informações e orientações sobre o seu funcionamento, recursos e funções. A partir da pesquisa de Bailly (2010), sobre o modo de utilização de uma determinada TD, os dados apontam que as pessoas desenvolvem novos conhecimentos sobre a ferramenta e, em perspectiva, podem analisar de que maneira essa utilização pode auxiliar no processo de aprendizagem em ambientes formais (institucionalizados) e informais (desinstitucionalizados).

Por meio do uso das TD, há a possibilidade de se localizar na rede o que se deseja, por vezes em diferentes línguas, verificar o contexto específico da publicação, informações sobre um autor, os assuntos que estão relacionados ao termo buscado e, todos esses elementos, na maioria das vezes, em tempo real. A atualização de conteúdo produzido na área científica, por exemplo, é indispensável para que o pesquisador possa produzir e publicar em um curto período de tempo. A socialização do conhecimento produzido na área é importante para que o desenvolvimento científico se efetive.

Com isso, a adoção das tecnologias digitais permite que haja a descentralização da informação para aqueles que têm acesso, possibilitando a aprendizagem de novos saberes, aumentando o repertório cultural e científico dos usuários. Na especificidade da aprendizagem de uma língua, Cassany (2011, p. 30, tradução nossa) defende que “[...] a formação leitura crítica educa o aluno na interpretação de opiniões (atitudes, pontos de vista, concepções, intenções, etc.) de um escrito, e não só na compreensão do seu conteúdo (principais ideias, inferências, etc.)".

Partindo do pressuposto de que a aprendizagem de línguas por meio das TD exige o uso consciente e, portanto, crítico do acesso aos conteúdos disponíveis na rede, considera-se que, independente do contexto no qual a aprendizagem se efetiva, a leitura crítica deva permear o cotidiano das pessoas.

Dito isso, observa-se que os indivíduos utilizam tecnologias para a aprendizagem de línguas, para além da leitura e de produções científicas. Há a utilização de recursos de fala, 
escrita, áudio e vídeo, além dos sites de relacionamento. Nesse contexto, as práticas de letramentos vernaculares clássicas estão presentes à medida em que as pessoas buscam o aprendizado básico sobre determinada tecnologia e, posteriormente, desenvolvem seus próprios meios de dar continuidade aos seus estudos, não consultando apenas produções científicas. As práticas vernaculares, portanto, fazem parte do cotidiano das pessoas e o uso das TD auxiliam no processo de aprendizagem, incluindo a construção do conhecimento sobre uma determinada língua.

Depois dessa contextualização do uso das TD, considera-se pertinente e relevante abordar, por meio da análise das entrevistas realizadas no âmbito da pesquisa em abordagem neste artigo, quais práticas de letramentos vernaculares as três licenciandas de Letras lançam mão para aprender a língua inglesa. Além disso, refletir-se-á sobre a utilização das práticas de letramentos vernaculares no cotidiano dessas entrevistadas.

\section{Práticas de letramentos vernaculares e aprendizagem da língua inglesa na visão das entrevistadas: análise dos dados}

Nesta seção, os dados da investigação empírica realizada por meio de um questionário e entrevistas semiestruturadas com estudantes do curso de Letras de uma universidade brasileira são apresentados e discutidos. O questionário foi aplicado com uma turma do curso de Letras em questão, no ano de 2016 e, posteriormente foram selecionadas três licenciandas pelas especificidades de suas trajetórias com a língua inglesa, para responderem a uma entrevista semiestruturada, que ocorreu em 2017.

O roteiro do questionário tinha como objetivo mapear práticas de letramentos na língua inglesa enquanto as entrevistas semiestruturadas visaram à compreensão de como essas licenciandas de Letras desenvolviam práticas vernaculares com TD para a aprendizagem da língua inglesa fora do currículo formal da universidade.

Como forma de alcançar o objetivo da entrevista, conforme mencionado anteriormente, foi utilizada a análise de conteúdo (BARDIN, 1977) para a categorização dos dados transcritos das entrevistas. Foram elaboradas, então, oito categorias de análise que estão relacionadas a duas grandes temáticas: 1) práticas de letramentos vernaculares com tecnologia que influenciam a aprendizagem da língua e refletem no contexto formal; 2) práticas de letramentos vernaculares que ressignificam a elaboração de planejamento pedagógico e a ação docente no contexto formal. 
As oito categorias de análise são: 1) práticas de leitura vernaculares em língua inglesa; 2) compreensão de vocábulos e o uso do tradutor para a leitura e/ou escrita de práticas vernaculares e acadêmicas em língua inglesa; 3) práticas vernaculares de escrita e oralidade em língua inglesa em interações sincrônicas através de sites/softwares de conversação para uso pessoal e profissional; 4) recomendações de sites/softwares específicos para a realização de práticas em língua inglesa; 5) busca de sites/softwares para realização de práticas de aprendizagem em língua inglesa; 6) materiais selecionados para a atuação docente em língua inglesa; 7) equipamentos midiáticos utilizados enquanto docente; e 8) crenças sobre a influência de práticas em língua inglesa com mídias digitais para o desenvolvimento pessoal, acadêmico e profissional.

No que diz respeito à primeira categoria de análise 'práticas de leitura vernaculares em língua inglesa', as entrevistadas mencionam que utilizam as TD para leitura em diferentes línguas, seja no tablet ou Kindle [suporte digital de leitura], e que esse uso torna o processo de aprendizagem mais fácil, rápido e barato. Além disso, os dados mostram que práticas de leitura vernaculares em língua inglesa, por meio da utilização do suporte digital, efetivam-se a partir de assuntos de interesse pessoal para as pesquisadas.

Nos depoimentos a seguir, há marcas de que as entrevistadas, mesmo utilizando as TD para práticas de letramentos vernaculares, têm preferências com relação à leitura em meio físico e digital e, também, privilegiam o acesso a alguns sites:

Eu prefiro ler no impresso. Gosto mais de ler no impresso, porque tem essa coisa do contato físico com o livro. [...] gosto de contos tipo de terror, ou romances, ou contos "short stories like", Irmãos Grimm, em língua inglesa. Prefiro físico por gostar da questão do toque mesmo [...] prefiro ler histórias mais curtas, de três, quatro, ou dependendo quinze páginas, dependendo do tamanho do conto. Já utilizei a interface digital. Baixar o PDF do livro os dos contos da Internet e ler no tablet. Mas o que eu prefiro, é ler o livro físico (Frida-Entrevista). ${ }^{5}$

Além de indicarem suas preferências de práticas de leitura vernaculares, as entrevistadas sinalizaram que tipo de leitura costumam fazer e quais sites são acessados:

[...] à noite quando eu chego em casa, que eu faço um "browsing" na Internet. Procuro um artigo de determinada área, de determinado assunto ou o próprio assunto. Então é de acordo com o que eu vou precisando no meu trabalho. E o que eu leio em língua estrangeira são coisas que eu me interesso. Normalmente, séries. Qualquer coisa que me interesse. Eu curto páginas no Facebook, de vários lugares diferentes: do New York Times,

${ }^{5}$ Os excertos dos depoimentos das entrevistadas estão grafados em itálico ao longo do texto. 
então aparece sempre atualizações pra mim, então aparece notícias as vezes, eu curto sites de artigos de blogs (Capitu - Entrevista).

Lia somente notícias ou frases curtas em suporte digital. Atualmente, tenho preferido ler no Kindle, que é digital, [...]. O primeiro livro que li em inglês comprei na Amazon norte americana, pois eu estava nos EUA na época. Posteriormente, passei a comprar livros, mesmo em inglês, na Amazon brasileira. Mas, a maioria dos livros que possuo, são fontes de download grátis dá internet. Até mesmo os em inglês (Catarina Entrevista).

Com esses depoimentos, compreende-se que Frida, ao contrário de Capitu e Catarina, deixou explícito preferir fazer a leitura no artefato físico, ao invés do digital. Também é perceptível a autonomia das licenciandas com relação à busca do conhecimento por meio de práticas de leitura vernaculares em língua inglesa. Capitu, por exemplo, estabelece uma rotina para práticas de leitura indicando "todo dia leio um pouquinho em inglês". A entrevistada ainda mencionou "eu prefiro ler na língua original, se eu sei a língua, né? Eu procuro livros em inglês, inclusive comprei o livro da série "Orange is the new black" (Capitu - Entrevista).

Portanto, os sites colaborativos e as lojas online estrangeiras, como mencionaram as entrevistadas, são uma alternativa para o acesso aos livros online na língua de origem, o que contribui para o aperfeiçoamento do conhecimento de outras línguas, principalmente, da língua inglesa. Por fim, as práticas de leitura vernaculares e o uso das TD auxiliam a aprendizagem da língua inglesa.

A segunda categoria de análise "compreensão de vocábulos e o uso do tradutor para a leitura e/ou escrita de práticas vernaculares e acadêmicas em língua inglesa" foi criada, visto que as três licenciandas utilizam o tradutor online para fazer a conversão de vocábulos ou expressões acadêmicas de uma língua para outra. Para exemplificar, em um dos depoimentos, Frida afirmou que "ferramentas de tecnologia, como os tradutores, possibilitam tirar as dúvidas quanto a tradução de alguns termos o que auxilia na compreensão e trabalho com textos teóricos" (Frida - Entrevista). Além disso, Frida indicou que quando surgiam dúvidas como relação à tradução de uma palavra em inglês, ela "abria o Google Tradutor, digitava em língua inglesa e procurava o significado em português" (Frida - Entrevista).

Com referência ao uso de um tipo de tradutor, todas as entrevistadas se referem ao Google Tradutor como uma das alternativas de tradução, porém Capitu afirma "eu não confio $100 \%$ no Google Tradutor e quando é pra alguma palavra mesmo eu vou direto no de inglês" (Capitu - Entrevista). Com isso, mesmo que utilizem o tradutor para a leitura ou escrita em práticas de letramentos vernaculares e acadêmicos em língua inglesa, para compreender os 
vocábulos, duas das depoentes, Capitu e Catarina, recorrem a outras ferramentas, como o dicionário monolíngue, além do Google Tradutor.

Com relação à terceira categoria de análise, "práticas vernaculares de escrita e oralidade em língua inglesa em interações sincrônicas através de sites/softwares de conversação para uso pessoal e profissional", as licenciandas deixaram claro realizar práticas vernaculares de escrita e oralidade em língua inglesa para desenvolvimento pessoal e profissional, porém com usos diferentes. Enquanto Frida acredita que o WhatsApp auxilia o contexto acadêmico para retirar dúvidas com professores e colegas, Capitu e Catarina utilizam o aplicativo em situações mais cotidianas, para conversar com amigos ou parentes próximos.

No que diz respeito ao aplicativo WhatsApp, Frida afirmou que "[...] no contexto acadêmico, também por conta de você poder tirar dúvidas, com professor via WhatsApp se quiser, ele te permite essa possibilidade. E tu consegue ter, manter contato, né? Com pessoas que falam em inglês. Então, ele ao meu ver, ele só tem benefícios" (Frida - Entrevista). Além do WhatsApp, Capitu indicou que utiliza também o Skype e o Facebook como ferramentas de conversação em língua inglesa, enquanto Catarina apontou outro elemento como importante no processo de conversação quando afirmou que "ao conversar com alguém procuro sempre sinônimos que eu conheça, quando não sei que termo utilizar. Caso eu não compreenda algo que a pessoa falou, aí sim, procuro pela tradução. Tradução normalmente é o último recurso que utilizo" (Catarina - Entrevista).

Com isso, os depoimentos indicam que as entrevistadas utilizam para fins pessoais e profissionais - de diferentes maneiras - práticas de letramentos vernaculares de escrita e de oralidade em língua inglesa.

A quarta categoria de análise, denominada "recomendações de sites/softwares específicos para a realização de práticas em língua inglesa" e a quinta categoria "busca de sites/softwares para realização de práticas de aprendizagem em língua inglesa" estão diretamente relacionadas à anterior, pois as entrevistadas já se referiram a algumas ferramentas que utilizam para a aprendizagem da língua inglesa. Conforme os depoimentos das entrevistadas, a indicação feita por colegas para a utilização de certos sites ou softwares, para o ensino e aprendizagem de línguas, influencia suas práticas de letramentos vernaculares, como se comprova com o depoimento de Catarina "lembro de colegas citarem o Duolingo, como aplicativo utilizado pra aprendizado" (Catarina - Entrevista). Além disso, a indicação realizada por professores também contribui para as práticas de leitura e escrita em língua inglesa como afirmou Frida, no excerto a seguir: 
[...] a professora acabou entrando e ensinando a gente a utilizar o dicionário Oxford, que ali a gente podia ter, a gente tinha a opção de procurar, é a palavra e vinha o termo técnico explicando o que significava em língua inglesa. $O$ que também amplia a competência linguística, o que amplia o contato com a língua, né? (Frida - Entrevista).

Assim, pode-se afirmar que as indicações de sites/softwares realizadas por colegas e professores auxiliaram as entrevistadas na realização de práticas em língua inglesa, contribuindo para suas aprendizagens e competências linguísticas. Além disso, a busca por sites/softwares, para realização de práticas de aprendizagem em língua inglesa como o Duolingo - citado por duas das entrevistadas, auxilia no aprendizado do nível básico de inglês. Nesse sentido, Frida mencionou o seguinte:

[...] eu estou sempre recomendando o Duolingo para as pessoas que estão no nível básico de Inglês porque é bem legal, vai fixando as estruturas. Achei maravilhoso, bem legal porque ele vai trabalhando bastante vocabulário várias vezes. Vai trabalhando bastante diferentes habilidades: uma hora você escuta, uma hora você escreve, uma hora você escuta o que você escreve, outra hora você fala. Então é como se você tivesse sempre interagindo em inglês com a máquina, né? Então, é muito interessante! Básico, porque as vezes, para uma pessoa que já tem um nível mais intermediário ou upper-intermediate, [...] é pouco, né? A pessoa já procura uma interação maior, desafios maiores, na minha opinião né? (Frida Entrevista).

A sexta categoria de análise, "materiais selecionados para a atuação docente em língua inglesa", e a sétima categoria, "equipamentos midiáticos utilizados enquanto docente”, estão relacionadas à medida em que são pesquisados materiais diferentes para o planejamento docente.

A entrevistada Frida afirmou "eu costumo utilizar o YouTube, no caso eu utilizava para planejamento de aula quando eu trabalhava com língua inglesa pra crianças e também no PIBID. Eu procurava vídeos no Youtube, de canais grandes como Captain English ou Disney Magic" (Frida - Entrevista). Já Catarina se referiu a outras ferramentas: "utilizo músicas para treinar a habilidade 'listening'. Eles gostam, pois a aula foge da rotina e do currículo. [...] quando trabalhava em escola de idiomas, utilizava também o quadro digital, com uma caneta especial, para jogos" (Catarina - Entrevista).

Conforme os depoimentos das entrevistadas, os materiais pesquisados para o planejamento pedagógico e para a ação docente são, na maioria das vezes, relacionados às TD, visto que a utilização das ferramentas midiáticas possibilita uma maior interação entre professores e estudantes e entre estudantes e estudantes. Essa constatação converge com a criação da última categoria de análise, "crenças sobre a influência de práticas em língua 
inglesa com mídias para o desenvolvimento pessoal, acadêmico e profissional". Com relação à criação de um grupo no aplicativo WhatsApp com uma turma de estudantes, a entrevistada Frida afirmou

Eu acho que influencia [utilizar as mídias para práticas vernaculares] de uma maneira boa. Porque tens a opção de pode digitar. [...] acaba praticando o 'writing', tu pratica o 'reading' também, se recebe alguma mensagem escrita. Como tu pode praticar também o 'speaking', porque o aplicativo também te permite a opção de mandar via áudio e tu ainda tem, também, a opção do 'listening'. Então, eu acho que o WhatsApp influencia bastante, porque ele permite que você trabalhe as quatro habilidades [ouvir,falar, ler e escrever] (Frida - Entrevista).

Com relação a esse aplicativo, Capitu ponderou que "as interações com a turma com WhatsApp funcionam muito bem. [...] tem uma característica negativa que, às vezes, o aluno se comunica [...] sábado à noite, dez horas. [...] todas as outras são positivas, porque eles acabam interagindo" (Capitu - Entrevista).

Nesse sentido, Catarina, ao se referir ao suporte tecnológico, converge com a opinião das outras entrevistadas, afirmando "acredito que levam o leitor/expectador a se interessar e buscar maior conhecimento acerca da língua. Acredito que utilizar um suporte tecnológico para qualquer tipo de relação com a língua inglesa levem a pessoa que utiliza a buscar mais sobre o assunto que a interessa" (Catarina - Entrevista).

A análise dos depoimentos possibilitou fazer algumas constatações acerca de práticas de letramentos vernaculares em língua inglesa no ambiente formal e informal de aprendizagem com o uso das TD. As estudantes convergem ao se manifestarem a respeito de que práticas vernaculares de leitura e de escrita com tecnologia influenciam a aprendizagem da língua inglesa e refletem no contexto formal. Portanto, as entrevistadas avaliaram que o uso das TD é importante para a aprendizagem da língua inglesa, tanto no que se refere ao seu uso cotidiano, quanto em suas práticas pedagógicas. Para finalizar, cabe ressaltar que as tecnologias são criações humanas e, como já referido anteriormente, devem ser utilizadas de maneira consciente nos diferentes contextos da vida.

\section{Considerações finais}

Os letramentos, compreendidos como conjunto de práticas sociais, manifestam-se com muitas particularidades em diferentes momentos e contextos históricos. Partindo dessa compreensão, objetivou-se, neste artigo, analisar que práticas vernaculares eram adotadas por 
licenciandas de Letras, no que se refere aos letramentos em língua inglesa, e examinar se as participantes faziam uso de algum recurso tecnológico para aprendizagem. Utilizou-se o conceito de práxis da aprendizagem visando à articulação entre os âmbitos educativo, político e a vida prática dos sujeitos inseridos nesse processo.

Considera-se que as TD devem ser utilizadas de maneira consciente, visto que são criações humanas e seu uso, na relação com o tema aqui abordado, deve auxiliar a aprendizagem da língua inglesa. Nesse sentido, as entrevistadas indicaram que as práticas vernaculares de leitura e escrita com tecnologia jogam um papel importante para a aprendizagem da língua inglesa nos seus usos cotidianos e em suas práticas pedagógicas.

Por fim, as práticas de letramentos vernaculares auxiliam a compreensão e execução de eventos e práticas oficiais em língua inglesa, como comprovou-se na manifestação das entrevistadas, e a universidade poderia potencializar esses movimentos autônomos de aprendizagem. Portanto, a partir das referências utilizadas como base teórica e as entrevistas realizadas com as licenciandas de Letras, compreende-se que as práticas de letramentos vernaculares em língua inglesa ressignificam a elaboração de planejamento pedagógico, a ação docente e, consequentemente a práxis na aprendizagem da língua inglesa para além do currículo formal da universidade.

\section{REFERÊNCIAS}

BAILLY, S. Supporting Autonomy Development in Online Learning Environments: What Knowledge and Skills do Teachers Need? In: Villanueva, M.; Ruiz, M. N. \& Luzon, J. (Eds.) Genres Theory and New Literacies: Applications to Autonomous Language Learning (pp.81-100). Cambridge: Cambridge Scholars Publishing, 2010.

BAILLY, S.; ASSIS, J.; DENEIRE, M. Ecrire et apprendre à écrire à l'université brésilienne, francaise et québécoise: questions de recherché en Didactique des Langues. Mélanges CRAPEL, 37(1), 5-9, 2016.

BARDIN, L. Análise de conteúdo. Lisboa: Edições 70, 1977.

BARTON, D. Literacy - an introduction to the ecology of written language. Cambridge/USA: Blackwell, 1994.

BARTON, D.; HAMILTON, M. Literacy practices. In: D. Barton et al. (Org.), Situated literacies: reading and writing in context (pp.7-15). London: Routledge, 2000.

BAUER, M. W.; GASKELL, G. Pesquisa qualitativa com texto, imagem e som: um manual prático. Petrópolis: Vozes, 2002. 
CASSANY, D.; CASTELlA, J. M. Aproximación a la literacidad crítica. Perspectiva, 28(2), 353-374, 2010.

CASSANY, D. Prácticas lectoras democratizadoras. Textos de Didáctica de la Lengua y de la Literatura, 58, 29-40, 2011.

CASSANY, D.; HERNÁNDEZ, D. ¿Internet: 1; Escuela: 0? CPU-e, Revista de Investigación Educativa, 14, 126-141, 2012.

CASSANY, D. Apropiación y uso del alfabeto español, Journal of Spanish Language Teaching, 1(1), 31-45, 2014a.

CASSANY, D. Cinco buenas prácticas de enseñanza con internet. Lenguaje y textos, 39, 3947, 2014b.

DIONÍSIO, M. L. Educação e os estudos atuais sobre o letramento. Revista Perspectiva, Florianópolis, 25 (1), 209-224, 2007.

ESCORCIA, D.; FENOUILLET, F. Quel rôle de la metácognition dans les performances en écriture? Analyse de la situation d'étudiants en sciences humaines et sociales. Revue Canadienne de l'Éducation, 34(2), 53-76, 2011.

FREIRE, P. Pedagogia da autonomia: saberes necessários à prática educativa. Rio de Janeiro: Paz e Terra, 1996.

FRITZEN, M. P. O olhar da etnografia no fazer pesquisa qualitativa: algumas reflexões teórico-metodológicas. In: FRITZEN, M. P.; LUCENA, M. I. P. (Orgs.). O olhar da etnografia em contextos educacionais: interpretando práticas da linguagem (pp.55-71). Blumenau: Edifurb, 2012.

GEE, J. P. Sociolinguistics and literacies: Ideology in discourses (2nd ed.). London: Taylor \& Francis, 1996.

LEA, M. R.; STREET, B. V. The "academic literacies" model: Theory and applications. Theory into Practice, 45(4), 368-377, 2006.

MCLUHAN, M. Os meios de comunicação como extensões do homem. São Paulo: Cultrix, 1995.

STREET, B. V. Literacy in theory and practice. Cambridge: CUP, 1984.

STREET, B. V. Entrevista concedida a Gilcenei Teodoro Carvalho e Marildes Marinho.

Revista Língua Escrita, 7(2), 84-92, 2009.

TRIVIÑOS, A. N. S. Introdução à pesquisa em Ciências Sociais: a pesquisa qualitativa em educação. São Paulo: Atlas, 1987.

TURNES, L. Pesquisa e pós-graduação: Um estudo de caso sobre os usos das tecnologias por parte de doutorandos (Unpublished masters thesis). Federal University of Santa Catarina, Florianópolis, 2014. 
VÓVIO, C. L.; SOUZA, A. L. S. Desafios metodológicos em pesquisas sobre letramento. In: Kleiman, A. \& Matêncio, M. L. M. (Orgs.), Letramento e formação do professor (pp.4164). Campinas: Mercado de Letras, 2005.

ZUIN, A. A. S. O plano nacional de educação e as tecnologias da informação e comunicação. Educação \& Sociedade, v. 31, n. 112, p. 961-980, 2010.

\section{Como referenciar este artigo}

FISTAROL, C. F.; FISCHER, A.; BAILER, C. Práticas de letramentos vernaculares em língua inglesa: a práxis na aprendizagem além do currículo formal da universidade. Revista Ibero-Americana de Estudos em Educação, Araraquara, v. 14, n. 4, p. 2358-2376, out./dez. 2019. e-ISSN: 1982-5587. DOI: https://doi.org/10.21723/riaee.v14i4.12719

Submetido em: 05/01/2019

Revisões requeridas: 30/03/2019

Aprovado em: 28/07/2019

Publicado em: 02/09/2019 